\title{
Trigeminal Autonomic Cephalalgia
}

National Cancer Institute

\section{Source}

National Cancer Institute. Trigeminal Autonomic Cephalalgia. NCI Thesaurus. Code C117074.

A headache disorder characterized by episodes of unilateral, short lasting pain and associated ipsilateral cranial autonomic symptoms. 